\title{
The need for knowledge translation in chronic pain
}

\author{
James L Henry PhD
}

\author{
JL Henry. The need for knowledge translation in chronic pain. \\ Pain Res Manage 2008;13(6):465-476.
}

One in five Canadians suffers from some form of persistent or chronic pain. The impact on individual lives, families and friends, the health services sector and the economy is huge. Reliable evidence is available that the burden of persistent pain can be markedly reduced when available knowledge is applied. Bridging the quality chasm between chronic pain and the care process will require a unique confluence of opinion from all stakeholders committed within a focused community of practice to address the impact of pain. Various levels of success in this regard have been demonstrated when there is exchange, synthesis and ethically sound application of research findings within a complex set of interactions among researchers and knowledge users. It is now critical to accelerate the capture of the benefits of research for Canadians through improved health, more effective and responsive services and products, and a strengthened health care system to bring about health reform and health care reform across Canada as it pertains to the one in five Canadians living with chronic, disabling pain. The overarching outcome of such an initiative needs to be promoted to sustain a balanced portfolio of curiosity- and needs-based research, which along with existing knowledge, can be mobilized and applied for the benefit of Canadians, the health care system and the economy.

Key Words: Chronic disease management; Chronic pain; Knowledge exchange; Organizational change; Research into practice; Research utilization

\section{La nécessité d'appliquer les connaissances sur la douleur chronique}

Un Canadien sur cinq souffre d'une forme de douleur persistante ou chronique. Les répercussions sur la vie personnelle, sur les familles et les amis, sur les services de santé et sur l'économie sont énormes. Selon des données probantes, il est possible d'atténuer considérablement le fardeau de la douleur persistante grâce à l'application des connaissances sur le sujet. Pour combler l'écart de qualité entre la douleur chronique et le processus des soins, il faut parvenir à une confluence d'opinions unique de la part de tous les intervenants engagés au sein d'une communauté de pratique ciblée afin d'aborder les effets de la douleur. Divers taux de réussite ont été démontrés à cet égard en présence d'échange, de synthèse et d'applications éthiquement solides des résultats des recherches dans un ensemble complexe d'interactions entre chercheurs et utilisateurs des connaissances. Il est maintenant essentiel d'accélérer le transfert des bienfaits de la recherche pour les Canadiens par une amélioration de la santé, par des produits et services plus efficaces et plus réactifs et par un système de santé renforcé afin d'assurer une réforme des soins et de la santé au Canada pour chacun des Canadiens sur cinq vivant avec une douleur chronique et débilitante. Il faut promouvoir les issues déterminantes d'une telle initiative pour maintenir un portefeuille équilibré de recherches axées sur la curiosité et sur les besoins qui, conjointement avec les connaissances existantes, peut être mobilisé et appliqué au profit des Canadiens, du système de santé et de l'économie.

\footnotetext{
Clause 4 of Bill C-13, the Canadian Institutes of Health Reseach (CIHR) Act of the Canadian Parliament (1), states:
}

The objective of the CIHR is to excel, according to internationally accepted standards of scientific excellence, in the creation of new knowledge and its translation into improved health for Canadians, more effective health services and products and a strengthened Canadian health care system...

Research generating knowledge in pain is attempting to understand mechanisms, complexities, incidence and prevalence, and the personal, social and economic costs, etc. While much remains to be learned, at the same time we must recognize that we are much further ahead than we were 20 years ago, or even 10 years ago. An important question, though, is how much this mounting knowledge is being applied to those who suffer debilitating pain, which is the presumed end-purpose of knowledge generation. This is the entry point for 'knowledge translation', the term widely used to refer to the process of research use or the application of knowledge to receptor communities. More formally, knowledge translation at CIHR is defined as the exchange, synthesis and ethically sound application of research findings within a complex set of interactions among researchers and knowledge users - to accelerate the capture of the benefits of research for Canadians through improved health, more effective services and products, and a strengthened health care system.

How important is knowledge translation to the area of pain chronic or persistent pain in particular? The present overview is designed to argue that Canada, the Canadian health care system, Canadian society and the Canadian economy are in dire need of application of knowledge translation and exchange to debilitating pain. In fact, a national strategy is needed to promote implementation of research findings, application and appraisal of clinical practice guidelines, and uptake of decision support tools by health care practitioners and decisionmakers.

\section{KEEPING IN STEP WITH SHIFTING NEEDS}

Effective knowledge translation initiatives must be directed at ensuring that Canadians live well, as free from undue pain and suffering as possible, engaging consumer patients and their local caregivers, along with academic, health service delivery, voluntary sectors and government organizations as a community of practice directed at implementing and sustaining capacitybuilding initiatives throughout Canada in support of health 
care renewal, navigating the complexities of ensuring that systems of care are available when patients and families need them. Terms used in this document are adapted from references 2 and 3 , and <www.ewenger.com>.

The World Health Organization has recognized the shift in needs of health care, from the acute model to a chronic disease model. Irrespective of the level of prosperity, health care systems worldwide face disparities in access to care, and limitations in assets and resources. Policy and service decision-makers face the challenge of matching these limited assets and resources to the changing needs, to make significant improvements in caring for chronic conditions. Leadership combined with a willingness to embrace change and innovation will have far more impact than simply adding capital to health care systems. In the World Health Organization's Innovative Care for Chronic Conditions (4) it is stated that:

Health care is organized around an acute, episodic model of care that no longer meets the needs of many patients, especially those with chronic conditions. Decreases in communicable diseases and the rapid aging of the population have produced this mismatch between health problems and health care, and chronic conditions are on the rise. Patients, health care workers, and most importantly, decision-makers, must recognize that effective chronic condition care requires a different kind of health care system. The most prevalent health problems such as diabetes, asthma, heart disease, and depression require extended and regular health care contact. Appropriate management often involves medications and always requires that patients make lifestyle adjustments to manage their persistent health problems. Health care systems that are based upon an acute care model cannot meet these demands.

Pain is increasingly recognized, managed and treated as a disease (5). An abundance of data is revealing that chronic pain imposes a heavy burden on sufferers and their families, the health care system, the workplace and the economy. Demographics indicating an aging Canadian population and the increasing disability from pain with increasing age should alert us to a looming crisis in pain care, beyond the crisis that already exists today. Models of health care are evolving globally from being predominantly cure-oriented; these models are poorly equipped to meet population needs for comprehensive care of chronic conditions. A system change is needed to adapt Canadian health care to chronic disease management because the current system is held back by insufficient uptake of reliable information on the part of all stakeholders, by current funding mechanisms and priorities, and by established health care policies.

Illness is the doctor to whom we pay most heed: to kindness, to knowledge we make promises only; pain we obey - Marcel Proust

\section{CHRONIC DISEASE MANAGEMENT-THE CALL FOR A PARADIGM SHIFT}

The United States (US) National Coalition on Health Care published a report in May 2002 (6), in which EH Wagner stated:
The good news is that care of chronic illnesses has become substantially more effective through recent progress in clinical and behavioural treatments. When properly applied to well-informed patients, newer treatments can lead to major reductions in suffering and avoid complications. But the bad news is that studies show that only a minority of people with these conditions is receiving appropriate treatment. Especially lacking is support for patients' efforts to manage their own health.

Crossing the Quality Chasm, published recently by the Institute of Medicine (7), highlighted this discrepancy (ie, the chasm) between the medical care made possible by advances in clinical and behavioural therapies, and the care received by the majority of patients. Deficiencies in quality of care have traditionally been attributed to the failings of doctors and other health care providers, but the Institute of Medicine report shifts that focus from the providers to the systems in which they work - "Current care systems cannot do the job. Trying harder will not work. Changing systems of care will."

In the paragraphs below, it will be pointed out that chronic pain inflicts a heavy burden on individual Canadians, the Canadian health care system and the Canadian economy. The means to bring about improvement in all these domains exist today. The chronic disease management model in Figure 1 is modified from the original by Glasgow et al (8).

\section{CHRONIC PAIN AS A DISEASE}

Not all pain is a disease. Pain is a protector to us most of the time, at least for those of us who do not live with constant pain. Acute pain, such as that following trauma or surgery, constitutes a signal to a conscious brain about the presence of noxious stimuli and/or ongoing tissue damage. This acute pain signal is useful and adaptive, warning the individual of danger and the need to escape or seek help. Acute pain is a direct outcome of the noxious event, and is reasonably classified as a symptom of underlying tissue damage or disease. When the original disorder resolves, so do its symptoms.

For some, though, pain is a constant companion, persisting long after its usefulness as an alarm signal has passed, and indeed, often long after the tissue damage has healed. Chronic pain in these patients may not be directly related to their initial injury or disease condition, but rather to secondary changes including some that occur in the pain detection system itself. Thus, the mechanisms underlying chronic or persistent pain may be quite different from acute pain. It is becoming increasingly clear that mechanisms are triggered that sustain the pain even when the cause is no longer active. Take phantom limb pain, for example - the painful limb may be removed, yet the pain persists $(9,10)$. Postherpetic neuralgia is too often a lasting outcome of the cutaneous eruptions of herpes zoster infection $(11,12)$. The pain does not resolve when the original cause resolves. The same may be said of the neuropathic pain that persists after cutting certain intercostal nerves during open-chest surgery (13).

Chronic pain may also be considered as a disease somewhat akin to considering myocardial infarction as a disease. Myocardial infarction may be caused by smoking, hypertension or diabetes. Multiple factors contribute to the cause of myocardial infarction, but myocardial infarction is the disease. 


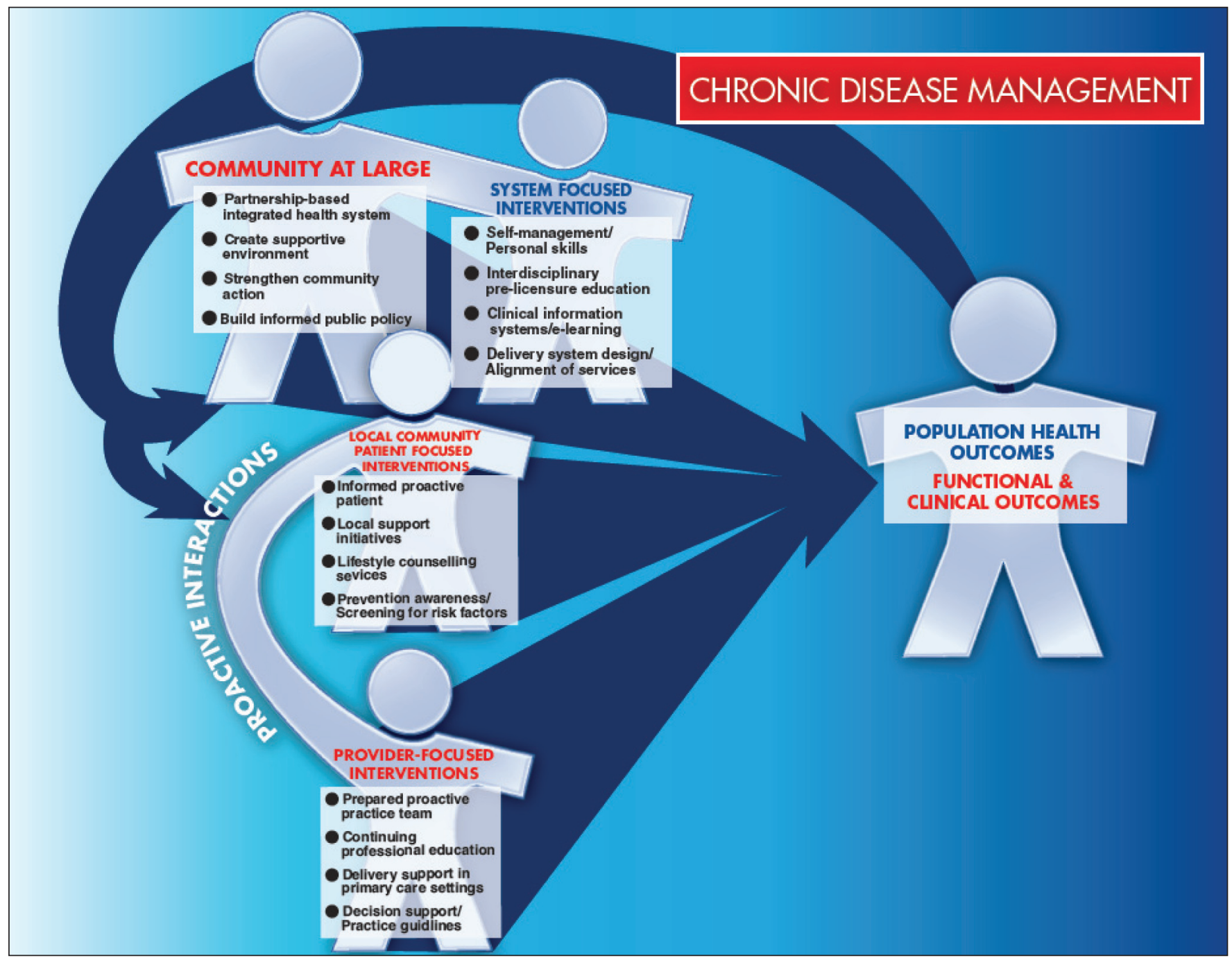

Figure 1) The burden of chronic diseases is tremendous, and traditional methods of health care delivery are unsuitable for addressing these needs. Chronic disease management has emerged as a new strategy for chronic disease care. Chronic disease management in the clinical setting is defined as an organized, proactive, multicomponent, patient-centred approach to health care delivery that involves all members of a defined population who have a specific disease entity (or a subpopulation with specific risk factors). Care is focused on, and integrated across, the entire spectrum of the disease and its complications, the prevention of comorbid conditions, and relevant aspects of the delivery system. Essential components include identification of the population, implementation of clinical practice guidelines or other decision-making tools, implementation of additional patient-, provider-or health care system-focused interventions, the use of clinical information systems, and the measurement and management of outcomes. It is said that few die from pain, yet many die in pain and even more live in pain

Similarly, it can be argued that persistent pain is a disease, and can result from multiple conditions.

The European Federation of International Association for the Study of Pain Chapters views chronic pain as a disease (14), and they have lobbied the European Parliament to declare chronic pain as a disease.

Pain is a major healthcare problem in Europe. Although acute pain may reasonably be considered a symptom of disease or injury, chronic and recurrent pain is a specific healthcare problem, a disease in its own right (15).

Chronic pain as a disease is also not without precedent. It can be argued that trigeminal neuralgia is painful and is a disease, as are migraines. Central poststroke pain is not a symptom, but a lasting disease.
Chronic pain differs from acute pain not only with regard to pathophysiology, but also with regard to associated features. Chronic pain often sets the stage for the emergence of a complex set of physical and psychosocial changes that are an integral part of the chronic pain problem and add greatly to the burden on the pain patient. These include immobility and consequent wasting of muscle, joints, etc; depression of the immune system and increased susceptibility to disease, fatigue, disturbed sleep, poor appetite and nutrition; dependence on medication; overdependence on family and other caregivers; overuse and often inappropriate use of professional health care systems; poor performance on the job or inability to work; disability; isolation from society and family; and turning inwards, anxiety, fear, bitterness, frustration, depression and suicide (16).

Let us consider the overall impact of chronic pain and its summation of symptoms and comorbidities. Is it such a 
problem that a system-wide paradigm shift in management and treatment will have a significant effect?

\section{THE BARE FACTS ABOUT CHRONIC PAIN}

\section{Types of chronic pain}

Chronic pain can arise from sundry causes. Some of the more common types of chronic pain include those of osteoarthritis, rheumatoid arthritis, low back, shoulder and neck, headache (including migraine), cancer pain, myofascial pain syndromes, post-thoracotomy pain, chronic regional pain syndromes, stump and phantom limb pain, neuropathic pain, herpes zoster (shingles) and postherpetic neuralgia, trigeminal neuralgia, diabetic neuropathy, temporomandibular joint disorder, postmastectomy pain, angina pectoris, chronic visceral pain syndromes, and others.

To date, there are no comprehensive figures outlining the incidence of the various chronic pain syndromes and their costs to Canadian society. However, investigators in various countries have begun to compile information of this nature, which illustrates the magnitude of suffering due to chronic pain.

\section{Prevalence of chronic pain}

In a random survey of 2012 Canadians, chronic pain was reported by $29 \%$ of respondents, with increased frequency in women and older age groups. The average duration of pain was 10.7 years and the average intensity was 6.3 on a 10-point scale. Almost 70\% of those reporting pain were worried about addiction (17). Estimates of the prevalence of activity limitations related to neck pain alone are in the range of $11 \%$ to $14 \%$ in both Ontario and Quebec $(18,19)$. However, this number is not universally acknowledged - according to workers' compensation statistics, work-related neck pain represents a minor health burden to Canadian society $(20,21)$.

Similar numbers were found in an Australian study (22) of 17,543 randomly selected interviewees; $17 \%$ of men and $20 \%$ of women reported experiencing pain every day for three months in the previous six months. In a United Kingdom (UK) study of 7878 respondents 50 years of age and older (23), $72 \%$ reported pain. The findings of a study in the Netherlands $(24,25)$ indicate that chronic pain is also a common complaint in childhood and adolescence, and severely impacts quality of life, including physical, psychological and functional status. An epidemiological survey of chronic pain in Sweden (26) found that $45 \%$ of all adults have experienced recurrent or persistent pain, and $8 \%$ have experienced severe persistent pain. A study carried out in Catalonia, Spain (27) reported a pain prevalence of $78.6 \%$ in response to telephone interviews asking about any pain complaint experienced in the past six months, regardless of its intensity and duration. A postal survey in Sweden (28) found that pain or discomfort, including problems of short duration, were reported by $66 \%$ of those questioned, with $40 \%$ reporting 'obvious' pain lasting more than six months. A broadly based epidemiological study of chronic pain in the Grampian region of the UK (29) found that $50 \%$ of those surveyed reported chronic pain or discomfort, including $16 \%$ with back pain and $16 \%$ with arthritis. In $16 \%$ of those surveyed, chronic pain was severe. Canadian numbers of prevalence therefore align with those found in similar studies in other jurisdictions.

\section{Impact of chronic pain}

Multifactorial issues surround chronic pain, where direct and indirect costs must be factored into assessing impact, as well as factors such as the high occurrence of comorbidity, attitude toward chronic pain and chronic pain patients among health care providers, fears and beliefs of chronic pain sufferers, fears of taking painkiller drugs, psychosocial context, etc. Thus, while the following paragraphs will include an attempt to address specific issues, these issues must be considered in the context that there is a close inter-relationship between all the factors.

\section{Chronic pain as a disability}

In a Canadian survey (17), almost one-half of those reporting chronic pain were unable to attend social and family events and the mean number of days absent from work per person in the past year due to chronic pain was 9.3. A Toronto study (30) indicated that among medical illnesses, chronic pain was the second major cause of suicide, only after bipolar disorder, and ahead of depression and psychotic disorder. Richard Holden, a former Member of the National Assembly in the Quebec Legislature who represented Westmount, left a suicide note indicating that his excruciating pain led him to suicide. Of 19 adults with disabling hip and knee osteoarthritis in a Toronto cohort (31), most had comorbidities such as heart disease and diabetes. Sadly, adherence to pain medication differed from that of other prescribed medications because participants were reluctant to take painkillers and when they did, they generally took them at a lower dose or frequency than prescribed.

Chronic pain is typically accompanied by a constellation of other disorders. Older persons, particularly women and the less educated, are most severely impacted and disabled by chronic pain $(23,29,32)$. In a US study of 55,686 patients with painful neuropathic disorders (33), older persons, women and the less educated were more likely to have other pain-related conditions, including fibromyalgia (6.0\%), osteoarthritis (13.6\%) and other chronic comorbidities such as coronary heart disease $(13.6 \%)$ and depression (6.4\%). In a European study of 18,980 randomly selected subjects (34), $16.5 \%$ reported a depressive symptom and of these, $27.6 \%$ had at least one type of chronic pain. Among the $4.0 \%$ diagnosed with major depressive disorder, $43.4 \%$ had at least one type of chronic pain. Neuropathic pain patients reported significantly more sleep disturbance and daytime somnolence as well as less quality and adequacy of sleep than patients in the general US population (35). Of 749 children and adolescents in a German study (36), 83\% had experienced pain during the preceding three months and reported that pain led to sleep problems $(54 \%)$, inability to pursue hobbies $(53 \%)$, eating problems $(51 \%)$, school absence (49\%) and inability to meet friends (47\%). A Scottish random sample of 4611 adults (37) indicated that the presence of 'any', 'significant' and 'severe' chronic pain had progressively more adverse associations with employment, and interfered with daily activities and all measured dimensions of general health. Individuals with spinal cord injuries and pain were more likely than those without pain to experience frequent interference with a variety of daily activities, including sleep (38). The pain had more negative effects on quality of life than the extent of the spinal injury (39). Of 255 patients with painful diabetic 
peripheral neuropathy in a US study (40), during the previous three months, $60 \%$ had two or more health professional consults, $59 \%$ reported decreased home productivity, $8.5 \%$ reported activity limitations and $64.4 \%$ of those who worked reported missing work or decreased productivity due to pain; $62.7 \%$ had other neuropathic and musculoskeletal pain conditions. Whether pain associated with multiple sclerosis (41), fibromyalgia $(42,43)$, herpes zoster $(44,45)$ or other disorders that carry chronic pain, the data reflect a huge impact of pain and increased likelihood of comorbid conditions.

In a recent review of patients referred to a Danish pain centre (46), mean pain severity was 7 on a 10 -point scale, quality of life measures were severely reduced, $58 \%$ had depression or anxiety disorder, $63 \%$ had neuropathic pain and $73 \%$ of these were taking opiates on referral even though this did not provide adequate pain relief. The study showed that health-related quality of life of chronic noncancer pain patients is among the lowest observed for any medical condition (46). Data from a study in Sweden (47) indicate that spinal pain is very common among men and women 35 to 45 years of age and that it is related to marked limitations in lifestyle for approximately one-quarter of those who experience pain.

Clearly, then, chronic pain must be recognized directly and indirectly through comorbidities as a major factor having an impact on the quality of life and the life habits of a large number of Canadians.

\section{Health services usage}

The 1994 to 1995 National Population Health Survey (48) indicated that 3.9 million Canadians, or $17 \%$ of the population over 15 years of age, suffer from chronic pain. Of those, $70 \%$ rated the pain as moderate to severe and as interfering with daily activities. Those with severe chronic pain made more physician visits (mean of 12.9 versus 3.8 visits) and stayed in hospital longer (mean of 3.9 versus 0.7 days) compared with those without any chronic pain in the previous year.

In a European study of 5803 people with musculoskeletal pain (49), up to $27 \%$ did not seek medical help. Of those who did see a doctor, several waited months or years; $55 \%$ of patients who saw a doctor are currently receiving drug treatment for their pain. Patients typically reported that communication with doctors was poor. Within the context that pain is the most common complaint of those suffering musculoskeletal conditions, it was reported (50) that in the US between 1990 and 1992, patients with musculoskeletal conditions made 315 million physician visits, had more than eight million hospital admissions and experienced approximately 1.5 billion days of restricted activity. A study in Finland (51) found that, from a pool of 5646 patient visits to primary health care services, $40 \%$ identified pain as the reason for their visit. One-fifth of patients reported having experienced pain for over six months. One-quarter of the pain patients of active working age were receiving paid sick leave. From an Australian stratified sample of 17,543 telephone interviews (32) with a $70.8 \%$ response rate, disability from chronic pain was associated with a greater number of primary care visits, hospital admissions and emergency department visits.

These data appear to implicate pain as a leading cause of health service usage by chronic pain patients, but dedicated surveys implicate factors beyond just the pain. While it is generally acknowledged that patients with chronic pain use health care services significantly more than persons without chronic pain, what is perhaps surprising is that less than one-third of the care is for the primary pain condition across different types of pain (51-54). Increased usage is often due to ill-defined conditions, lower priority chronic disease, acute disease and mental health care (55).

\section{Economic costs}

In view of efforts to align care along more economical avenues, it is interesting to note that in a study of the economic impact of chronic pain and disease in Canada (56), resource use measures were found to be driven more by disease prevalence than intensity of resource use. Costs associated with multiple sclerosis in Canada, for example, are reported to be positively correlated with levels of self-reported pain, with an estimated six-month overall burden of pain in multiple sclerosis patients to be over $\$ 79$ million (41).

In an attempt to quantify the total cost of chronic noncancer pain to the Irish economy in 1995, a study from a sample of 95 patients estimated that chronic pain had already cost the economy $£ 1.9$ million by the time of their referral to a multidisciplinary pain clinic (57). Total health care expenditures incurred by individuals with back pain in the US reached $\$ 90.7$ billion in 1998 (51), those for neck pain reached US\$686 million in the Netherlands in 1996 (58). In a study of 25 randomly selected Finnish health centres over a four-week period (59), 1123 patients visited general practitioners because of musculoskeletal pain. Laboratory tests were ordered for $12 \%$, imaging for $24 \%$, analgesics prescribed for $61 \%$ and sick leave prescribed for $25 \%$; the mean cost per patient was as high as $€ 530$ per visit. A study of the socioeconomic costs of pain syndromes in the UK (60) estimated the direct health care cost of back pain in 1998 to be $£ 1.6$ billion. However, this direct cost was considered to be insignificant compared with the cost of informal care and the related production losses, which totalled $£ 10.7$ billion. A US study of 16,567 patients in a retrospective administrative database analysis for the period 1996 to 2001 (61) reported that direct medical costs amounted to $\$ 357$ per month for each patient; the authors suggested a tailored approach to care for high utilisers. Specific numbers are also available for other types of chronic pain, including postherpetic neuralgia (44), neuropathic pain (62), multiple sclerosis (41), back and neck pain (63), rheumatoid arthritis (64) and others. It is important to note that overall costs for chronic pain care have been increasing despite the emergence of evidence-based guidelines $(63,65)$.

A German study of the usage of specialist care for low back pain found that 575 of 1342 patients were seeking specialist care. This high use of specialist care was attributed to the absence of a functioning primary care gate-keeping system for patient selection (66) and it was suggested that overall costs could be reduced with patient education, encouragement of physical activity and simple pain medications.

This section has examined direct costs. Let us now examine data on some of the indirect costs.

\section{Chronic pain and the workplace}

The Nuprin Pain Report (67), commissioned to study the impact of chronic pain in the US, revealed that patients with chronic pain had reduced capacity to work and enjoy life. The 


\section{PAIN in a CHRONIC DISEASE MANAGEMENT FRAMEWORK}

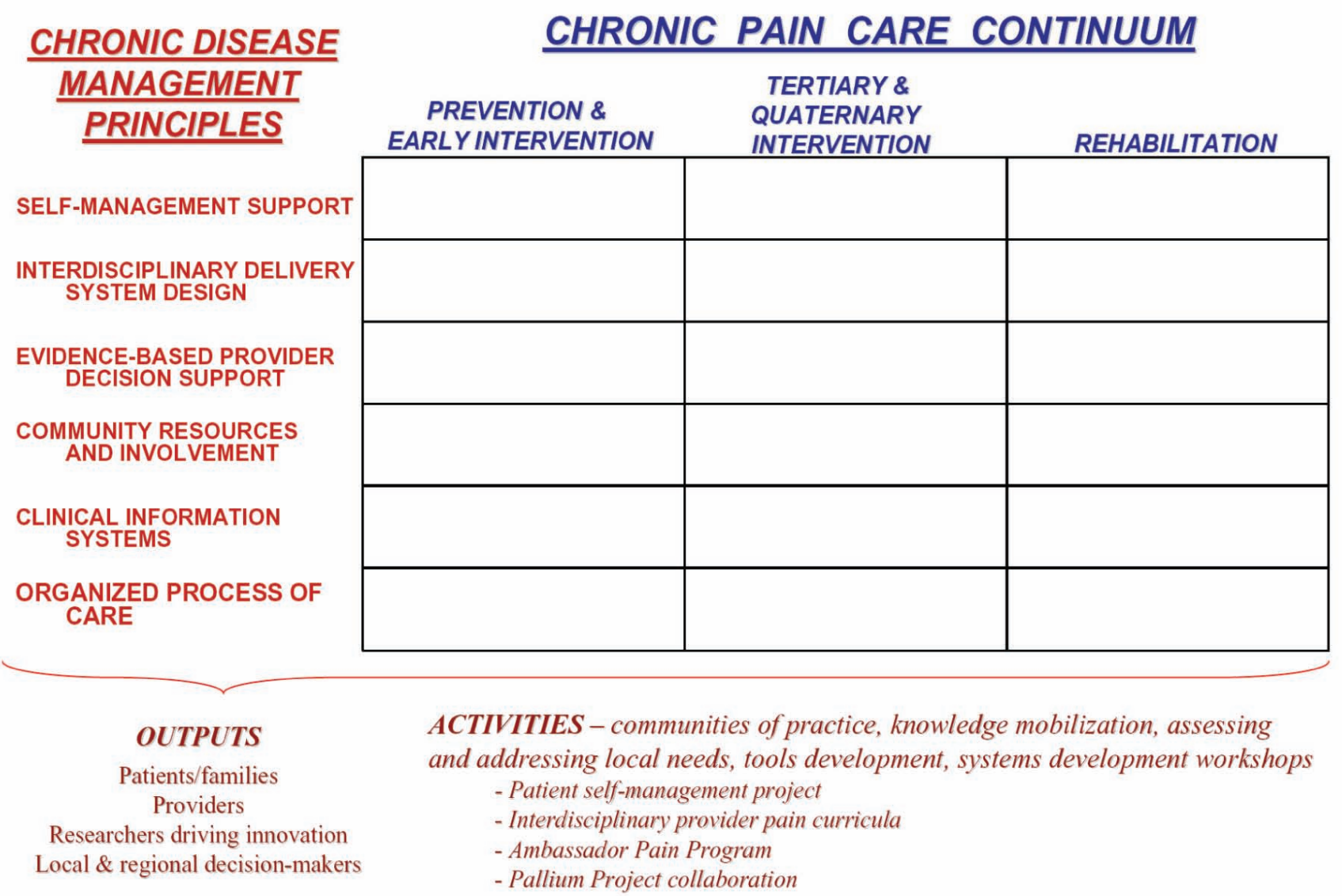

Figure 2) System change must be designed to address components of chronic disease management principles applied across the care continuum for chronic pain for a system-wide strategic action that draws on existing success stories in Canada and a care continuum perspective on factors impacting on health measures and quality of life. The framework is based on the wide range of health-related disciplines that must join forces if opportunities to reduce disability associated with chronic pain are to be realized. In this respect, it is essential that system-level change is accompanied by and supportive of the empowerment and active participation of individuals, their families and communities. The present project is a first step toward this change as a reality by moving evidence and applying it to the care continuum

annual number of lost days at work was estimated at four billion, or 23 days for every adult. In a Swedish study on low back pain (68), indirect costs for patients were largely due to absenteeism and reduced productivity, and constituted $85 \%$ of overall costs.

Data from the American Productivity Audit (69) indicated that, during a two-week period, $13 \%$ of the total work force experienced a loss in productive time due to a pain condition. Surprisingly, $76 \%$ of the lost productive time was through reduced performance while at work rather than from absenteeism $(69,70)$. Similar results were reported from an Australian study (71), in which chronic pain sufferers who worked with pain were more common (mean 83.8 days in six months) than chronic pain sufferers who lost work days due to pain (mean 4.5 days). A more recent Australian study (72) estimated that chronic pain sufferers lost 9.9 million work days due to chronic pain, equalling a cost of AU $\$ 1.4$ million. However, reduced effectiveness at work translated to 36.5 million lost work day equivalents, equalling $\mathrm{AU} \$ 51$ billion per year. A survey of 4839 chronic pain sufferers in Europe (73) showed that $61 \%$ were less able or unable to work outside the home, $19 \%$ had lost their jobs and 13\% had changed jobs because of their pain, $60 \%$ had visited their doctor about their pain two to nine times in the past six months, only $2 \%$ were being treated by a pain management specialist and $48 \%$ had inadequate management of their pain. A study in the Netherlands (74) found that musculoskeletal diseases are the fifth most expensive disease category regarding hospital care, and the most expensive regarding work absenteeism and disability $(1.7 \%$ of the gross national product). A recent systematic review of the costs of low back pain (75) concluded that economic costs, taking into account direct and indirect costs, must be considered a substantial burden on society. Interestingly, the review did not identify any studies estimating the costs from a societal perspective.

Data reported from the Alberta Workers' Compensation Board (76) indicated that there was significant improvement in return-to-work outcomes when a continuum of care model was implemented to guide rehabilitation service delivery, with a cost-savings of $\$ 21.5$ million over a two-year study period. 


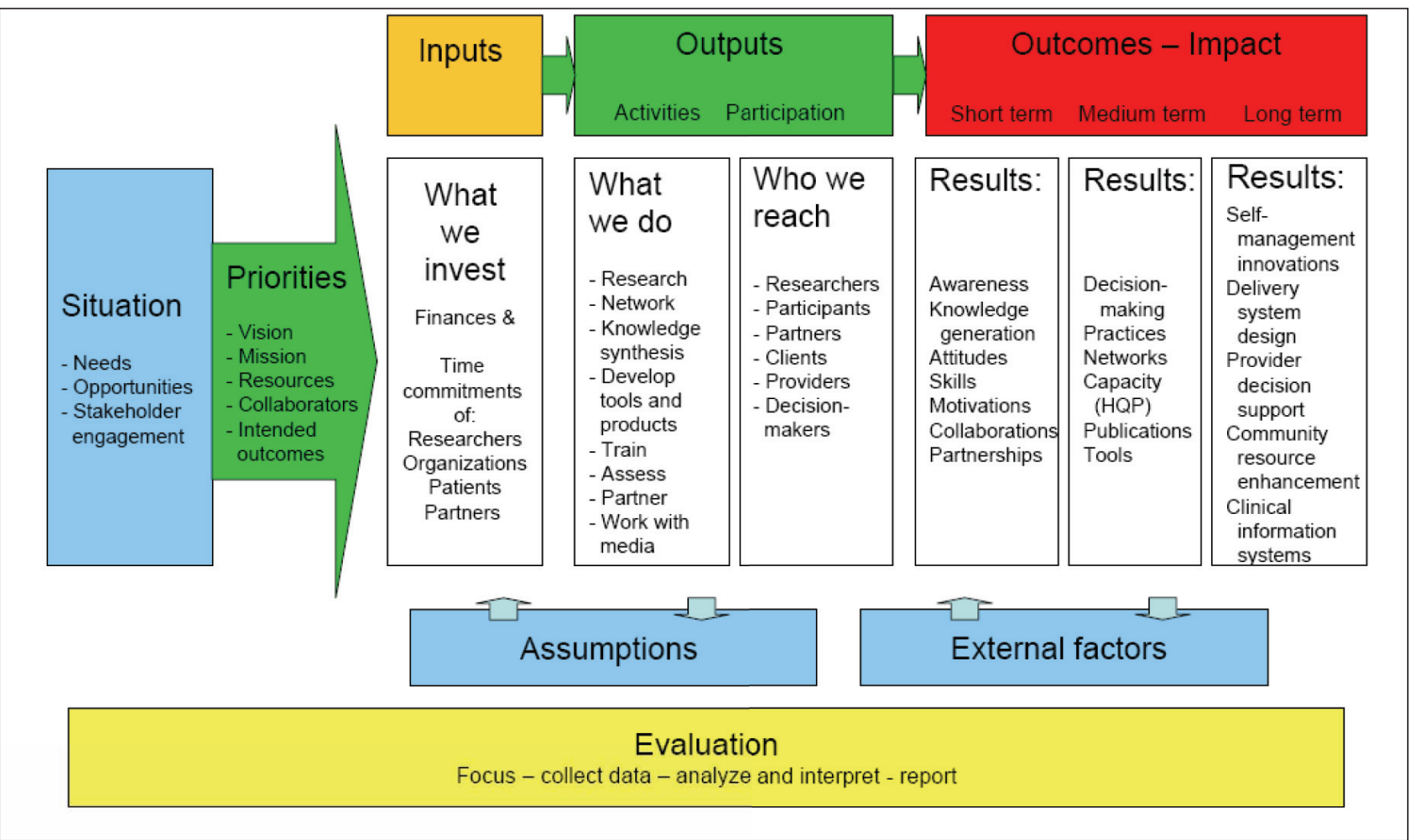

Figure 3) This logic model displays the sequence of actions that describe what the initiative is and will do, and how investments link to results. Five core components of initiative action are inputs (personnel and financial resources; contributions), outputs (engagement, participation, extrinsic knowledge, knowledge synthesis and dissemination), outcomes (creating, capturing, leveraging and retaining knowledge; capacity building through training, recruiting and retaining; changes for individuals, communities, organizations and systems), assumptions (core vision, values, beliefs, aspirations and tacit knowledge of researchers and partners) and external factors (the broader context within which this initiative operates; embedded knowledge)

\section{Adherence as a target for a knowledge translation strategy}

An extensive list of guidelines and systematic reviews is available from reliable sources for the management and treatment of chronic pain (77), and methods for assessment of evidencebased pain management are clearly laid out $(78,79)$. In fact, the plethora of guidelines and systematic reviews may be an obstacle to use; there is a systematic review of systematic reviews of low back pain (80) and a systematic review of low back pain guidelines (81).

There are too many guidelines to begin to list here, but the important issue is whether these guidelines are used and make a difference to the patient (65); limited research has addressed the impact of adherence to guideline recommendations on clinical outcomes and costs of care (82) and adherence to guidelines has been advocated to decrease the use of ineffective therapies and to improve patient outcomes and more costeffective care (83). On the one hand, a Montreal clinical trial confirmed that adherence to guidelines improves pain and functional status at six-month follow-up (84) and adherence to clinical guidelines for low back pain has been shown to have clinical and economic benefits $(85,86)$. However, management of low back pain in a cohort of general practitioners in Ireland was not consistent with European clinical guideline recommendations and it was found that most of the costs incurred were attributable to nonadherence (87). Barriers to using evidence-based guidelines include lack of time, insufficient skills, uncertainty and resistance to findings that challenge traditional practices $(88,89)$. Recognizing this gap between knowledge and practice, a call has been made to promote research into development of effective professional behaviour change interventions (90-92).

While clear guidelines are abundantly available, uptake is generally lacking, yet attitude appears to play an overarching influence. Thus, the patient-doctor interaction has been reported to play a pivotal role in patient outcome, governing whether this interaction "leads to a healing process or to a vicious circle of unnecessary utilization of services" (93).

\section{Attitude as a barrier to effective pain management} In a telephone survey of 2400 adults in Alberta and Saskatchewan (94), it was found that back pain beliefs among patients are not in harmony with current scientific evidence. Having access to appropriate information influences pain management outcomes. Attitude profiles of patients with chronic pain impact clinical status and quality of life $(95,96)$, as well as fear-avoidance beliefs, which occur early in low back pain patients (97), for example, and have been reported to negatively impact on patient outcome, patient disability and health care contacts (98-100).

Health care providers can play an important role in providing appropriate patient information and thus may influence patient fear-avoidance beliefs and reduce costs (101). We have come a long way from the concept of accepting mild pain as 


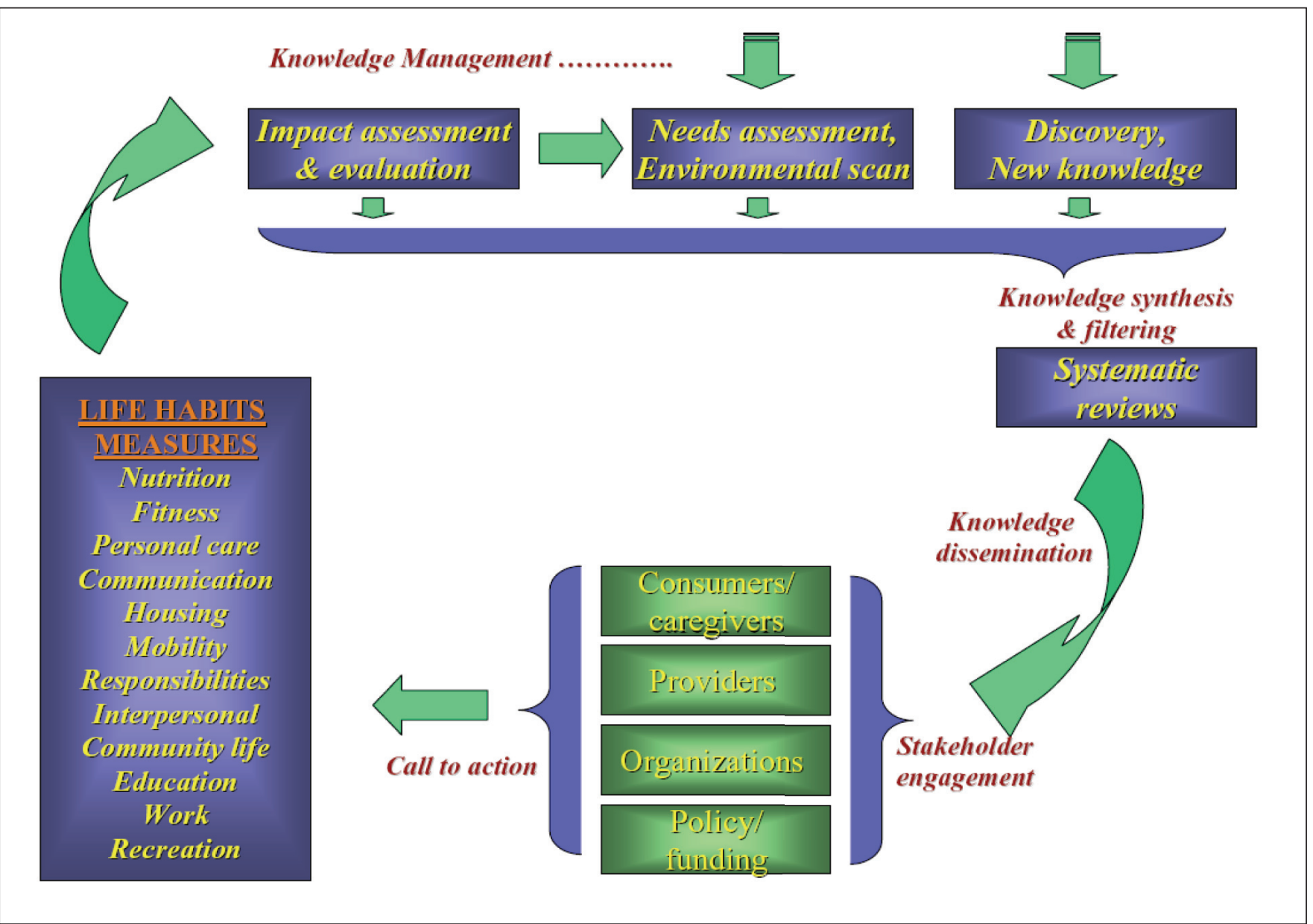

Figure 4) Knowledge management applied within an organizational framework ensures growth, continuity and sustainability because action outcomes are measured as life habits and quality of life, and these outcomes are applied to refresh the cycle of knowledge management. The entry point to this organizational framework can be at any point of a green arrow, including new discoveries, such as those from basic science laboratories (eg, the research of the principal investigator and his colleagues and beyond), but also from environmental scans and needs assessments. The organizational framework also maximizes opportunities for partnerships with nongovernmental organizations to participate in applying capacity with process to put evidence into practice

part of daily life (102). However, a recent search reported that adherence to guidelines is poor, with some health care professionals reluctant to change clinical practice (103). In fact, fearavoidance is still prevalent among health care professionals (104), and in a recent study of 864 general practitioners in France (105), their own fear-avoidance beliefs negatively influenced whether they followed guidelines for their patients with low back pain. Similar results have been associated with general practitioners in the UK (106) as well as specialists $(106,107)$. This impact of attitude on pain management outcome underscores the need to explore ways to ensure transfer of research findings into clinical practice.

\section{CONCLUSIONS}

Chronic pain is considered a chronic disease that imposes a heavy burden on patients and caregivers, on the health care system and on the economy. Chronic pain is generally undertreated and under-managed in the current health care environment in Canada. This burden translates to need related to functional impairment, due to the disease of chronic pain coupled with the disability that it creates.
Based on the evidence above, it is clear that there are measures that can be established to address the burden of chronic pain from the perspective of international standards of life habits. These can include nutrition, fitness, personal care, communication, housing, mobility, responsibilities, interpersonal relations, community life, education, work, and recreation.

Evidence is available that specific approaches to health care, deriving from the chronic disease management model outlined above, if applied, can improve these outcomes measures. This evidence translates to opportunity and calls for system change.

System change can come when, within a research environment, multistakeholder communities of practice bring together patients and their home and community caregivers, with motivated health care providers and informed community partners within a positive policy environment. These constituents may be brought together through the logic model outlined below. Chronic pain crosses all health care sectors, and shows a marked comorbidity with other chronic diseases. Thus, system change in chronic pain care should serve to improve outcomes in other chronic diseases in addition to pain. 


\section{The chronic care model}

It is generally understood that the chronic pain patient is often a complex patient and, as several different factors have been shown to correlate with or be predictive of chronic pain, there are increasing calls to incorporate management approaches that are effective across illnesses $(55,61)$. We shall examine one of these models developed to address optimal approaches to management of chronic illness. The Chronic Care Model is an evidence-based, conceptual framework developed first by Wagner et al (108). In the ACT Report of May 2002 (6), Wagner outlines a road map for a set of system changes that can increase optimal care, and includes the following list, rearranged from the original. Through a managed approach to research, it may be possible to incorporate these six areas to improve outcomes for people suffering chronic pain in Canada.

Self-management support: There is now considerable evidence that individual and group interventions that promote patient empowerment and the acquisition of self-management skills are effective in diabetes, asthma and other chronic conditions. They emphasize the crucial role that patients play in setting goals, establishing action plans, identifying barriers to effective selfmanagement and problem-solving to overcome the barriers.

Delivery system design: Planned visits and active follow-up are central to assuring high-quality chronic illness care. Planned visits use relevant patient information, evidence-based guidelines and organized approaches to assure that all patients receive recommended services. Such visits can be individual or in groups, and include attention to self-management and preventive interventions, as well as acute problems. High-quality chronic illness care also requires close follow-up of the patient's condition and treatments. This can be done by telephone or e-mail, as well as in person. Many of the critical follow-up tasks do not require clinical training and could be most efficiently and consistently performed by nonprofessional team members.

Provider decision support: Data indicate that guidelines become effective behaviour-change agents for health care providers only when they are woven into the fabric of patient care through effective professional education, reminders, and ongoing feedback and reinforcement. Guideline adherence can be increased by incorporating guidelines into a registry, flow sheets and patient assessment tools coupled with educational support from clinical opinion leaders such as medical specialists.

Community resources: Organizations large and small, in urban and rural areas, in solo practices and in integrated health systems have found that community resources supplement and support their efforts to improve the care of patients with chronic illnesses. Chronically ill patients can benefit from a variety of services and resources that are not available from their health care provider, such as educational offerings, peer support groups and exercise programs. Increasing access to effective community resources through linkages with relevant organizations and agencies is a cost-effective way to optimize care.

Clinical information systems: A registry or database of key information on all patients with a chronic condition is the glue that holds an effective chronic care system together. Registries facilitate monitoring and planning care for individual patients and for the practice as a whole. An effective registry reminds caregivers of needed services and can generate materials for providers and patients that support planned visits. To enhance the care for the practice as a whole an effective registry provides feedback on performance and can identify which patients are in particular need of attention.

A supportive health care organization: Given the challenges of packed appointment schedules and tighter budgets, changes at the level of practice are unlikely to happen unless it is a priority for the organization and its leaders. Strong senior leadership plays an instrumental role in providing motivation, securing resources and removing the barriers that may stall quality improvement activities.

\section{EXECUTION PLAN}

$$
\begin{aligned}
& \text { Knowing is not enough; we must apply. } \\
& \text { Willing is not enough; we must do. } \\
& \text { - Goethe }
\end{aligned}
$$

To focus on these areas, system change must address the chronic pain gap through a structured framework such as the one illustrated in Figure 2.

\section{Logic model for the research themes as communities of practice}

A logic model, such as that illustrated in Figure 3, identifies linkages between the activities of a programme and the achievement of its outcomes. It succinctly clarifies the set of activities that make up the programme and the sequence of outcomes that are expected to flow from these activities. The logic model is an illustration of how the activities of the programme are expected to lead to the achievement of the final outcomes.

In Nonaka's reformulation of Polyani's definitions (109), extrinsic knowledge is knowledge that the individual holds explicitly and consciously in mental focus, and may communicate to others. Tacit knowledge is often subconscious, internalized, and the individual may or may not be aware of what he or she knows and how he or she accomplishes particular results. Some also use the term 'embedded knowledge', which is knowledge that is embedded in a process but not in an explicit way; that is, it requires other knowledge for it to be extracted (110).

This logic model can be applied in planning, implementation, evaluation and communication.

Organizational framework: The next step is to fit this logic model into an organizational framework designed to create a favourable environment for execution, to assess and evaluate impact and success, and promote clearly defined stakeholder engagement. An example is illustrated in Figure 4.

The following considerations are an attempt to outline research pathways that require adequate funding support to address the needs outlined above. These considerations are directed toward synergizing activities to make a compelling case for further large scale funding obtained from a variety of sources. The case is made for infrastructure support that will enable comprehensive research programs that focus on:

1. Pain cause and cure research;

2. Research on maximizing effectiveness and efficiency of health and social services support for the clientele of interest with a focus on disability that addresses enhanced life habits participation, prevention of deterioration, and optimization of health services usage to address the huge burden of chronic pain; and 
3. Knowledge mobilization that puts evidence-informed innovations, as per steps 1 and 2, into practice and evaluates the effectiveness of these innovations.

A coordinated approach to managed research is necessary to promote exchange and sharing of specific goals, methods, tools and assessments between active participants, to ensure crossdiscipline learning, direction and strategy.

\section{Partnering strategy}

Partnership development will be an ongoing program. As research initiatives evolve, new opportunities for partnership will announce themselves, and a mobilizing plan for action will be developed and pursued based on shared vision and common values, which will build commitment, engage participants and use participants' time well. The purpose will be to recruit and engage active and sustained involvement of additional participants in the action plan, with clearly defined benefits to this coordinated effort and to the partners, as well as to raise additional funds to enable new initiatives to be undertaken beyond those currently available. Broad representation must be sought from local public health system partners, other community organizations, and community residents. Participants will need to identify resource needs and determine sources for meeting those needs. For each partner, tools such as a project proposal, a master calendar and action-linked agendas must be developed. A process for clarifying assignments and managing the work must also be outlined.

\section{The case for action in context}

Bridging the quality chasm between chronic pain and the care process will come from a unique confluence of opinion from all stakeholders committed within a focused community of practice to address the impact of chronic pain on the one in five Canadians who suffer chronic, debilitating pain. Need for improvement in care is announced abundantly in the literature. Operational solutions with traction must be applied to this national burden through an organizational logic model to support mainstream structures at the local level. At the outset, specific action items that must be addressed will include a survey and inventory of needs, best practices, and an inventory of services and gaps coupled with stakeholder validation of gaps, preferences and priorities. It is anticipated that through activities involving all stakeholder groups, a national initiative will develop a defensible case for a paradigm shift in health, based on the principle that the generation, translation and diffusion of evidence is the purview and product of research-community engagement if reliable knowledge is to be socially robust.

The overarching impact anticipated from the outputs of a managed approach to research is to promote and sustain a balanced portfolio of curiosity-based and needs-based research which, along with existing knowledge, can be mobilized and applied for the benefit of Canadians, the Canadian health system and the Canadian economy. This would have to be accomplished through the key outcomes of improving effectiveness and efficiency of health and social services support for those who suffer chronic, debilitating pain with a focus on disability that addresses enhanced life habits participation, prevention of deterioration, and optimization of health service usage to address the huge burden of chronic pain disorders and disabilities.

The added value of such a national program is as follows. Creation of a unified stakeholder voice to make recommendations for public and voluntary sector policy development to address the huge burden of chronic pain. Creation of a defensible case for research-community interactions in this domain, to ensure that reliable knowledge addresses burden by being socially robust. Enhancement of the funding base supporting operations and, on this basis, potential for leverage from the public purse, for incremental funding.

\section{CONCLUSIONS}

Pain has traditionally been seen as secondary to something else the result is undertreated or untreated pain, unnecessary suffering, heavier reliance on the health care system, loss of productivity in the work force, absenteeism, increased comorbidity, and a cycle of illness that overall exacts a heavy toll on Canadians and the Canadian economy. Reliable evidence is available that these burdens can be markedly reduced when available knowledge is applied. Various levels of success in this regard have been demonstrated when there is exchange, synthesis and ethically sound application of research findings within a complex set of interactions among researchers and knowledge users. A nationally based managed approach to pain research is needed to accelerate the capture of the benefits of research for Canadians through improved health, more effective and responsive services and products, and a strengthened health care system through promoting and integrating success stories in health reform and health care reform across Canada.

ACKNOWLEDGEMENTS: The author gratefully acknowledges input from Dr Richard Riopelle, McGill University, regarding chronic disease management frameworks and logic models.

\section{REFERENCES}

1. Canadian Institutes of Health Research Act (2000, c. 6). <http://

laws.justice.gc.ca/en/C-18.1/index.html> (Version current at December 1, 2008).

2. Graham ID, Logan J, Harrison MB, et al. Lost in knowledge translation: Time for a map? J Cont Educ Health Profess 2006;26:13-24.

3. Wenger E. Communities of practice learning as a social system. <http://www.co-i-l.com/coil/knowledge-garden/cop/lss.shtml> (Version current at November 25, 2008).

4. Epping-Jordan, J. Innovative Care for Chronic Conditions. Geneva: World Health Organization, 2002:68.

5. Siddall PJ, Cousins MJ. Persistent pain as a disease entity: Implications for clinical management. Anesth Analg 2004;99:510-20.

6. Wagner EH. Diabetes, childhood asthma, depression, hypertension, heart disease, rheumatoid arthritis. In: Curing the System: Stories of Change in Chronic Illness Care. Washington: National Coalition on Health Care Improvement, 2002:6-9.

7. Institute of Medicine (US) Committee on Quality of Health Care in America. Crossing the Quality Chasm. Washington: National Acadamy Press, 2001.

8. Glasgow RE, Orleans CT, Wagner EH, Curry SJ, Solberg LI. Does the chronic care model serve also as a template for improving prevention? Milbank Q 2001;79:579-612.

9. Mishra S, Bhatnagar S, Gupta D, Diwedi A. Incidence and management of phantom limb pain according to World Health Organization analgesic ladder in amputees of malignant origin. Am J Hosp Palliat Care 2007;24:455-62. 
10. Rasmussen S, Kehlet H. Management of nerves during leg amputation - a neglected area in our understanding of the pathogenesis of phantom limb pain. Acta Anaesthesiol Scand 2007;51:1115-6.

11. Johnson R, McElhaney J, Pedalino B, Levin M. Prevention of herpes zoster and its painful and debilitating complications. Int J Infect Dis 2007;11(Suppl 2):S43-8.

12. Sadosky A, McDermott AM, Brandenburg NA, Strauss M. A review of the epidemiology of painful diabetic peripheral neuropathy, postherpetic neuralgia, and less commonly studied neuropathic pain conditions. Pain Pract 2008;8:45-56.

13. Mailis A, Chan J, Basinski A, et al. Chest wall pain after aortocoronary bypass surgery using internal mammary artery graft: A new pain syndrome? Heart Lung 1989;18:553-8.

14. Niv D, Devor M. Chronic pain as a disease in its own right. Pain Pract 2004;4:179-80.

15. International Association for the Study of Pain and the European Federation of IASP Chapters. Unrelieved pain is a major global healthcare problem. <http://www.efic.org/04A\%20Global\%20 Day\%20Fact\%20Sheet.pdf $>$ (Version current at December 1, 2008).

16. Jessop DS. Brain-immune interactions in arthritis: An integrated systems approach. Arthrit Rheum 2008;58:2928-30.

17. Moulin DE, Clark AJ, Speechley M, Morley-Forster PK. Chronic pain in Canada - prevalence, treatment, impact and the role of opioid analgesia. Pain Res Manage 2002;7:179-84.

18. Côté P, Kristman V, Vidmar M, et al. The prevalence and incidence of work absenteeism involving neck pain: A cohort of Ontario losttime claimants. Spine 2008;33(Suppl 4):S192-8.

19. Leroux I, Dionne CE, Bourbonnais R, et al. Prevalence of musculoskeletal pain and associated factors in the Quebec working population. Int Arch Occup Environ Health 2005;78:379-86.

20. Workplace Safety \& Insurance Board (WSIB). 2005. < http://www. wsib.on.ca.libaccess.lib.mcmaster.ca/wsib/wsibobj.nsf/LookupFiles/D ownloadableFile2005StatisticalSupplement/\$File/2278A_StatSup. pdf $>$ (Version not current).

21. Saskatchewan Workers' Compensation Board. Statistical Supplement 2003. <http://www.wcbsask.com.libaccess.lib.mcmaster. ca/WCBPortal/ShowProperty/WCBRepository/formsPublications/ publications/annualPubs/2005StatisticalSummary/pdfContent> (Version not current)

22. Blyth FM, March LM, Brnabic AJ, Jorm LR, Williamson M, Cousins MJ. Chronic pain in Australia: A prevalence study. Pain 2001;89:127-34.

23. Thomas E, Peat G, Harris L, Wilkie R, Croft PR. The prevalence of pain and pain interference in a general population of older adults: Cross-sectional findings from the North Staffordshire Osteoarthritis Project (NorStOP). Pain 2004;110:361-8

24. Perquin CW, Hazebroek-Kampschreur AAJM, Hunfeld JAM, et al. Pain in children and adolescents: A common experience. Pain 2000;87:51-8.

25. Hunfeld JAM, Perquin CW, Duivenvoorden HJ, et al. Chronic pain and its impact on quality of life in adolescents and their families. J Pediatr Psychol 2001;26:145-53.

26. Von Korff M, Dworkin SF, Le Resche L. Graded chronic pain status: An epidemiologic evaluation. Pain 1990;40:279-91.

27. Bassols A, Bosch F, Campillo M, Canellas M, Banos J-E. An epidemiological comparison of pain complaints in the general population of Catalonia (Spain). Pain 1999;83:9-16.

28. Brattberg G, Thorslund M, Wilkman A. The prevalence of pain in a general population. The results of a postal survey in a county of Sweden. Pain 1989;37:215-22.

29. Elliott AM, Smith BH, Penny KI, Smith WC, Chambers WA The epidemiology of chronic pain in the community. Lancet 1999;354:1248-52.

30. Juurlink DN, Herrmann N, Szalai JP, Kopp A, Redelmeier DA. Medical illness and the risk of suicide in the elderly. Arch Intern Med 2004;164:1179-84.

31. Sale JEM, Gignac M, Hawker G. How "bad" does the pain have to be? A qualitative study examining adherence to pain medication in older adults with osteoarthritis. Arthritis Rheum 2006;55:272-8.

32. Blyth FM, March LM, Brnabic AJM, Cousins MJ. Chronic pain and frequent use of health care. Pain 2004;111:51-8.

33. Berger A, Dukes EM, Oster G. Clinical characteristics and economic costs of patients with painful neuropathic disorders. J Pain 2004;5:143-349.
34. Ohayon MM, Schatzberg AF. Using chronic pain to predict depressive morbidity in the general population. Arch Gen Psychiatry 2003;60:39-47.

35. Hays RD, Martin SA, Sesit AM, Spritzer KL. Psychometric properties of the medical outcomes study sleep measure. Sleep Med 2005;6:41-4

36. Roth-Isigkeit A, Thyen U, Stoven H, Schwarzenberger J, Schmucker P. Pain among children and adolescents: Restrictions in daily living and triggering factors. Pediatrics 2005;115:152-62.

37. Smith BH, Elliott AM, Chambers WA, Smith WC. The impact of chronic pain in the community. Fam Pract 2001;18:292-9.

38. Widerstrom-Noga EG, Felipe-Cuervo E, Yezierski RP. Chronic pain after spinal injury: Interference with sleep and daily activities. Arch Phys Med Rehabil 2001;82:1571-7.

39. Westgren N, Levi R. Quality of life and traumatic spinal cord injury. Arch Phys Med Rehabil 1998;79:1433-9.

40. Gore M, Brandenburg NA, Hoffman DL, Tai K, Stacey B. Burden of illness in painful diabetic peripheral neuropathy: The patients' perspectives. J Pain 2006; 7:892-900.

41. Piwko C, Desjardins OB, Bereza BG, et al. Pain due to multiple sclerosis: Analysis of the prevalence and economic burden in Canada. Pain Res Manage 2007;12:259-65.

42. Berger A, Dukes E, Martin S, Edelsberg J, Oster G. Characteristics and healthcare costs of patients with fibromyalgia syndrome. Int J Clin Pract 2007;61:1498-508.

43. White LA, Birnbaum HG, Kaltenboeck A, Tang J, Mallett D, Robinson RL. Employees with fibromyalgia: Medical comorbidity, healthcare costs, and work loss. J Occup Environ Med 2008;50:13-24.

44. Barrett AM, Lucerno MA, Le T, Robinson RL, Dworkin RH, Chappell AS. Epidemiology, public health burden, and treatment of diabetic peripheral neuropathic pain: A review. Pain Med 2007;8:S50-62

45. Dworkin RH, White R, O'Connor B, Raser O, Hawkins K. Healthcare costs of acute and chronic pain associated with a diagnosis of herpes zoster. J Am Geriatr Soc 2007;55:1168-75.

46. Becker N, Bondegaard TA, Olsen AK, Sjorgren P, Bech P, Eriksen J. Pain epidemiology and health related quality of life in chronic nonmalignant pain patients referred to a Danish multidisciplinary pain center. Pain 1997;73:393-400.

47. Linton SJ, Hellsing AL, Hallden K. A population based study of spinal pain among 35-45 year olds: Prevalence, sick leave, and health-care utilization. Spine 1998;23:1457-63.

48. Statistics Canada. National Population Health Survey - 1994/1995. <http://www.statcan.gc.ca/dli-ild/meta/nphs-ensp/1994/nphs1996ensp1996-1-eng.pdf> (Version current at December 1, 2008).

49. Woolf AD, Zeidler H, Haglund U, et al; on behalf of the Arthritis Action Group. Musculoskeletal pain in Europe: Its impact and a comparison of population and medical perceptions of treatment in eight European countries. Ann Rheum Dis 2004;63:324-47.

50. Yelin E, Callahan LF; for the National Arthritis Data Work Group. The economic cost and social and psychological impact of musculoskeletal conditions. Arthritis Rheum 1995;38:1351-62.

51. Mantyselka P, Kumpusalo E, Ahonen R, et al. Pain as a reason to visit the doctor; a study in Finnish primary health care. Pain 2001;89:175-80.

52. Luo X, Pietrobon R, Sun SX, Liu GG, Hey L. Estimates and patterns of direct health care expenditures among individuals with back pain in the United States. Spine 2004;29:79-86.

53. Engel CC, Von Korff M, Katon WJ. Back pain in primary care: Predictors of high health care costs. Pain 1996;65:197-204.

54. Levy RL, Von Korff M, Whitehead WE, et al. Costs of care for irritable bowel syndrome patients in a health maintenance organization. Gastroenterology 2001;96:3122-9.

55. Von Korff M, Lin EH, Fenton JJ, Saunders K. Frequency and priority of pain patients' health care use. Clin J Pain 2007;23:400-8.

56. Rapoport J, Jacobs P, Bell NR, Klarenbach S. Refining the measurement of the economic burden of chronic diseases in Canada. Chronic Dis Can 2004:25:13-21.

57. Sheehan J, McKay J, Ryan M, Walsh N, O'Keeffe D. What cost chronic pain? Ir Med J 1996;89:218-9.

58. Borghouts JAJ, Koes BW, Vondeling H, Bouter LM. Cost-of-illness of neck pain in the Netherlands in 1996. Pain 1999;80:629-36.

59. Mantyselka PT, Kumpusalo EA, Ahonen RS, Takala JK. Direct and indirect costs of managing patients with musculoskeletal pain challenge for health care. Eur J Pain 2002;6:141-8. 
60. Maniadakis N, Gray A. The economic burden of back pain in the UK. Pain 2000;84:95-103.

61. Ritzwoller DP, Crounse L, Shetterly S, Rublee D. The association of comorbidities, utilization and costs or patients identified with low back pain. BMC Musculoskeletal Disord 2006;7:72.

62. Rodriquez MJ, Garcia AJ. A registry of the aetiology and costs of neuropathic pain in pain clinics. Results of the Registry of Aetiologies and Costs (REC) in Neuropathic Pain Disorders Study. Clin Drug Invest 2007;27:771-82.

63. Martin BI, Deyo RA, Mirza SK, et al. Expenditures and health status among adults with back and neck problems. J Am Med Assoc 2008;299:656-64.

64. Jacobsson LTH, Lindroth Y, Marsal L, Juran E, Bergstrom U, Kobelt G. Rheumatoid arthritis: What does it cost and what factors are driving those costs? Results of a survey in a community-derived population in Malmo, Sweden. Scand J Rheumatol 2007;36:179-83

65. Asche CV, Kirkness CS, McAdam-Marx, C, Fritz JM. The societal costs of low back pain. Pall Care Pharmacotherap 2007;21:25-33.

66. Chenot JF, Leonhardt C, Keller S, et al. The impact of specialist care for low back pain on health service utilization in primary care patients: A prospective cohort study. Eur J Pain 2008;12:275-83.

67. Taylor H, Curran NM. The Nuprin Pain Report. New York: Louis Harris, 1985:1-233.

68. Ekman M, Jonhagen S, Hunsche E, Jonsson L. Burden of illness of chronic low back pain in Sweden. Spine 2005;30:1777-85.

69. Stewart WF, Ricci JA, Chee E, Morganstein D. Lost productive work time costs from health conditions in the United States: Results from the American Productivity Audit. J Occup Environ Med 2003;45:1234-46.

70. Stewart WF, Ricci JA, Chee E, Hirsch AG, Brandenburg NA. Lost productive time and costs due to diabetes and diabetic neuropathic pain in the US workforce. J Occup Environ Med 2007;49:672-9.

71. Blyth FM, March LM, Nicholas MK, Cousins MJ. Chronic pain, work performance and litigation. Pain 2003;103:41-7.

72. van Leeuwen MT, Blyth FM, March LM, Nicholas MK, Cousins MJ. Chronic pain and reduced work effectiveness: The hidden cost to Australian employers. Eur J Pain 2006;10:161-6.

73. Breivik H, Collett B, Ventafridda V, Cohen R, Gallacher D. Survey of chronic pain in Europe: Prevalence, impact on daily life, and treatment. Eur J Pain 2006;10:287-333.

74. van Tulder MW, Koes BW, Bouter LM. A cost-of-illness study of back pain in the Netherlands. Pain 1995;62:233-40.

75. Dagenais S, Caro J, Haldeman S. A systematic review of low back pain cost of illness studies in the United States and internationally. Spine J 2008;8:8-20.

76. Stephens B, Gross DP. The influence of a continuum of care model on the rehabilitation of compensation claimants with soft tissue disorders. Spine 2007;32:2898-904.

77. Chou R. Special section: Evidence-based medicine in low back pain - part 1, evidence-based medicine and the challenge of low back pain: Where are we now? Pain Pract 2005;5:153-70.

78. Grimshaw J, McAuley LM, Bero LA, et al. Systematic reviews of the effectiveness of quality improvement strategies and programmes. Qual Saf Health Care 2003;12:298-303.

79. Manchikanti L, Heavner JE, Racz GB, et al. Methods for evidence synthesis in interventional pain management. Pain Physician 2003;6:89-111.

80. Furlan AD, Clarke J, Esmail R, Sinclair S, Irvin E, Bombardier C. A critical review of reviews on the treatment of chronic low back Pain. Spine 2001;26:E155-62.

81. van Tulder MW, Tuut M, Pennick V, Bombardier C, Assendelft WJJ. Quality of primary care guidelines for acute low back pain. Spine 2004;29:E357-62.

82. Lesho EP, Myers CP, Ott M, Winslow C, Brown JE. Do clinical practice guidelines improve processes or outcomes in primary care? Mil Med 2005;170:243-6.

83. Grimshaw JM, Winkens RA, Shirran L, et al. Interventions to improve outpatient referrals from primary care to secondary care. Cochrane Database Syst Rev 2005;(3):CD005471.

84. Rossignol M, Abenhaim L, Seguin P, et al. Coordination of primary health care for back pain. A randomized controlled trial. Spine 2000;25:251-9

85. McGuirk B, King W, Govind J, Lowry J, Bogduk N. Safety, efficacy, and cost effectiveness of evidence-based guidelines for the management of acute low back pain in primary care. Spine 2001;26:2615-22.

86. Molde Hagen E, Grasdal A, Eriksen HR. Does early intervention with a light mobilization program reduce long-term sick leave for low back pain: A 3-year follow-up study. Spine 2003;28:2309-15.

87. Fullen BM, Maher T, Bury G, Tynan A, Daley LE, Hurley DA. Adherence of Irish general practitioners to European guidelines for acute low back pain: A prospective pilot study. Eur J Pain.

88. Grol R, Dalhujsen J, Thomas S, Veld C, Rutten G, Mokkink H. Attributes of clinical guidelines that influence use of guidelines in general practice: Observational study. BMJ 1998;317:858-61.

89. Cabana MD, Rand CS, Powe NR, et al. Why don't physicians follow clinical practice guidelines? A framework for improvement. JAMA 1999;282:1458-65.

90. Grimshaw JM, Shirran L, Thomas R, et al. Changing provider behavior: An overview of systematic reviews of interventions. Med Care 2001;39:112-45.

91. van Tulder MW, Croft PR, van Spulunteren P, et al. Disseminating and implementing the results of back pain research in primary care. Spine 2002;27:E121-7.

92. Fritz JM, Cleland A, Brennan GP. Does adherence to the guideline recommendation for active treatments improve the quality of care for patients with acute low back pain delivered by physical therapists? Med Care 2007;45:973-80.

93. Dahan R, Borkan J, Brown JB, Reis S, Hermoni D, Harris S. The challenge of using the low back pain guidelines: A qualitative research. J Eval Clin Pract 2007;13:616-20.

94. Gross DP, Ferrari R, Russell AS, et al. A population-based survey of back pain beliefs in Canada. Spine 2006;31:2142-5.

95. Tait RC, Chibnall JT. Attitude profiles and clinical status in patients with chronic pain. Pain 1998;78:49-57.

96. Keeley P, Creed F, Tomenson B, Todd C, Borglin G, Dickens C. Psychosocial predictors of health-related quality of life and health service utilization in people with chronic low back pain. Pain 2008;135:142-50.

97. Coudeyre E, Tubach F, Rannou F, et al. Fear-avoidance beliefs about back pain in patients with acute LBP. Clin J Pain 2007;23:720-5.

98. Fritz JM, George SZ, Delitto A. The role of fear-avoidance beliefs in acute low back pain: Relationships with current and future disability and work status. Pain 2000;94:7-15.

99. Pincus T, Burton AK, Vogel S, et al. A systematic review of psychological factors as predictors of chronicity/disability in prospective cohorts of low back pain. Spine 2002;27:E109-20.

100. Sullivan MJ, Adams H, Rhodenizer T, Stanish WD. A psychosocial risk factor-targeted intervention for the prevention of chronic pain and disability following whiplash injury. Phys Ther 2006;86:8-18.

101. Houben RM, Ostelo RW, Vlaeyen JW, et al. Health care providers' orientations towards common low back pain predict perceived harmfulness of physical activities and recommendations regarding return to normal activity. Eur J Pain 2005;9:173-83.

102. Cook AJ, Thomas MR. Pain and the use of health services among the elderly. J Aging Health 1994;6:155-72.

103. Bishop A, Thomas E, Foster NE. Health care practitioners' attitudes and beliefs about low back pain: A systematic search and critical review of available measurement tools. Pain 2007;132:91-101.

104. Poiraudeau S, Rannou F, Baron G, et al. Fear-avoidance beliefs about back pain in patients with subacute low back pain. Pain 2006; $124: 305-11$.

105. Coudeyre E, Rannou F, Tubach F, et al. General practitioners' fearavoidance beliefs influence their management of patients with low back pain. Pain 2006;124:330-7.

106. Bishop A, Foster NE, Thomas E, Hay EM. How does the self-reported clinical management of patients with low back pain relate to the attitudes and beliefs of health care practitioners? A survey of UK general practitioners and physiotherapists. Pain 2008;135:187-95.

107. Poiraudeau S, Rannou F, Le Henanff A, et al. Outcome of subacute low back pain: Influence of patients' and rheumatologists' characteristics. Rheumatol 2006;45:718-23.

108. Wagner EH, Davis C, Schaefer J, Von Korff M, Austin B. A survey of leading chronic disease management programs: Are they consistent with the literature? Manage Care Q 1999;7:56-66.

109. Nonaka I. A dynamic theory of organizational knowledge creation. Organization Science 1994;5:14-37.

110. Madhavan R, Grover R. From embedded knowledge: New product development as knowledge management. J Mark 1998;62:1-12. 


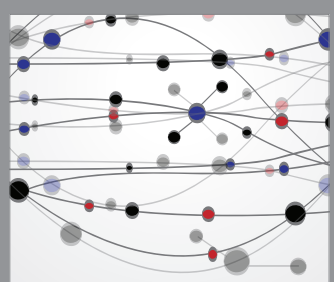

The Scientific World Journal
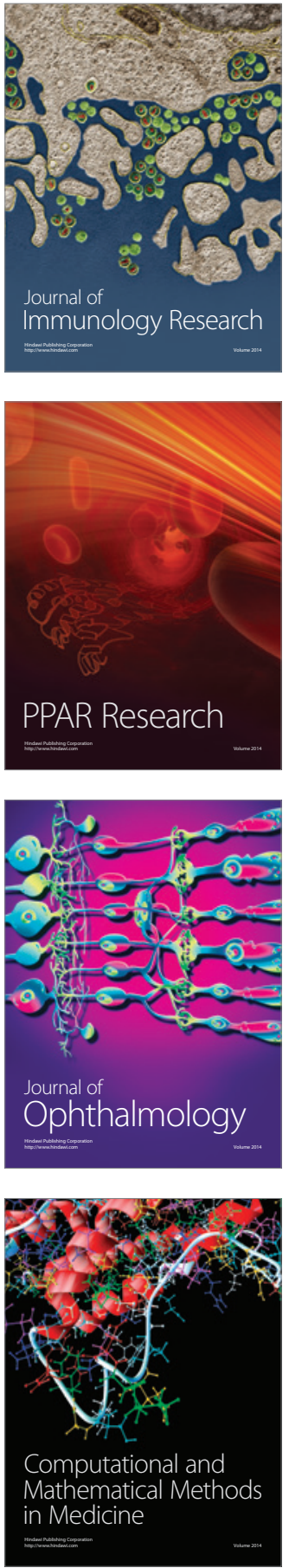

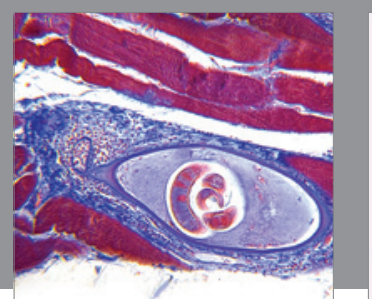

Gastroenterology Research and Practice

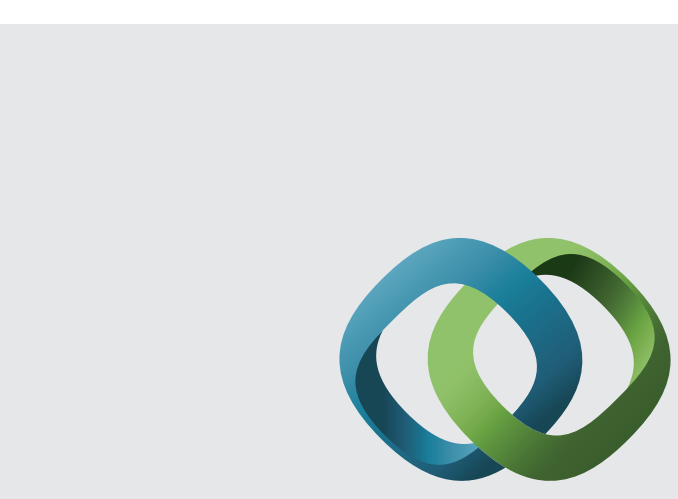

\section{Hindawi}

Submit your manuscripts at

http://www.hindawi.com
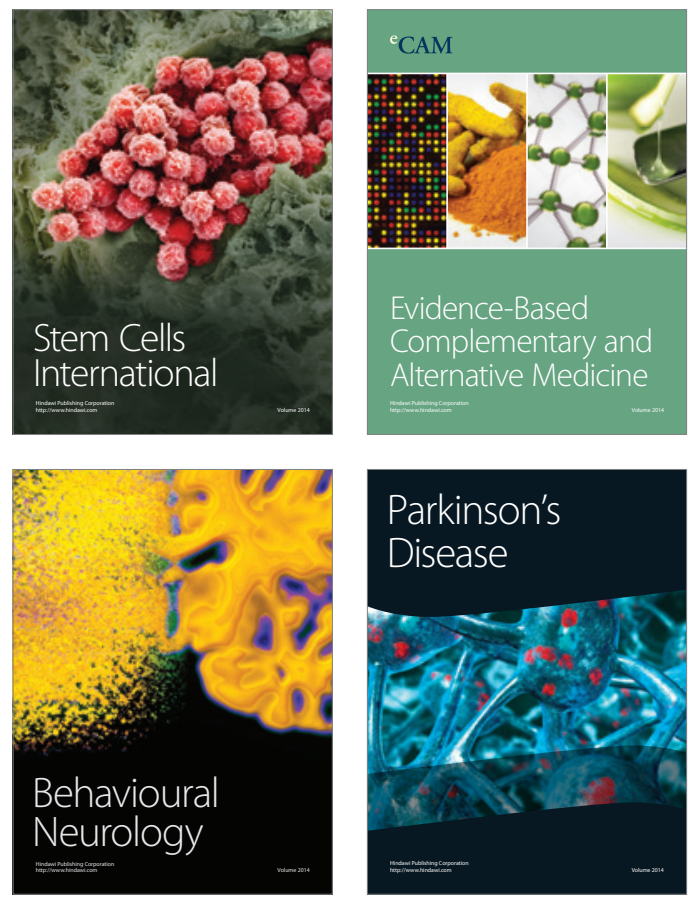
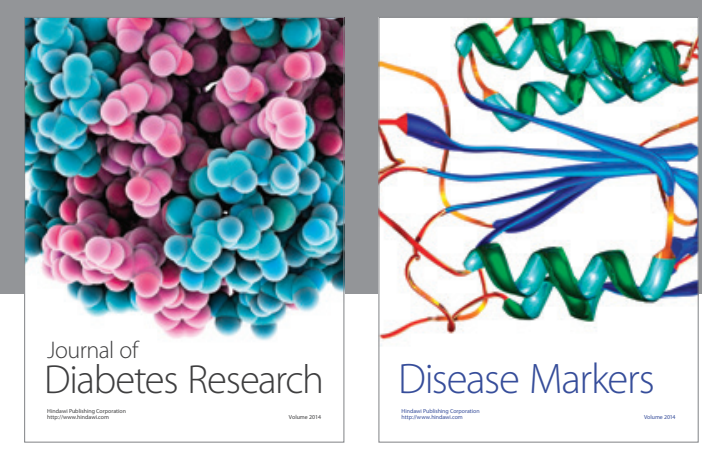

Disease Markers
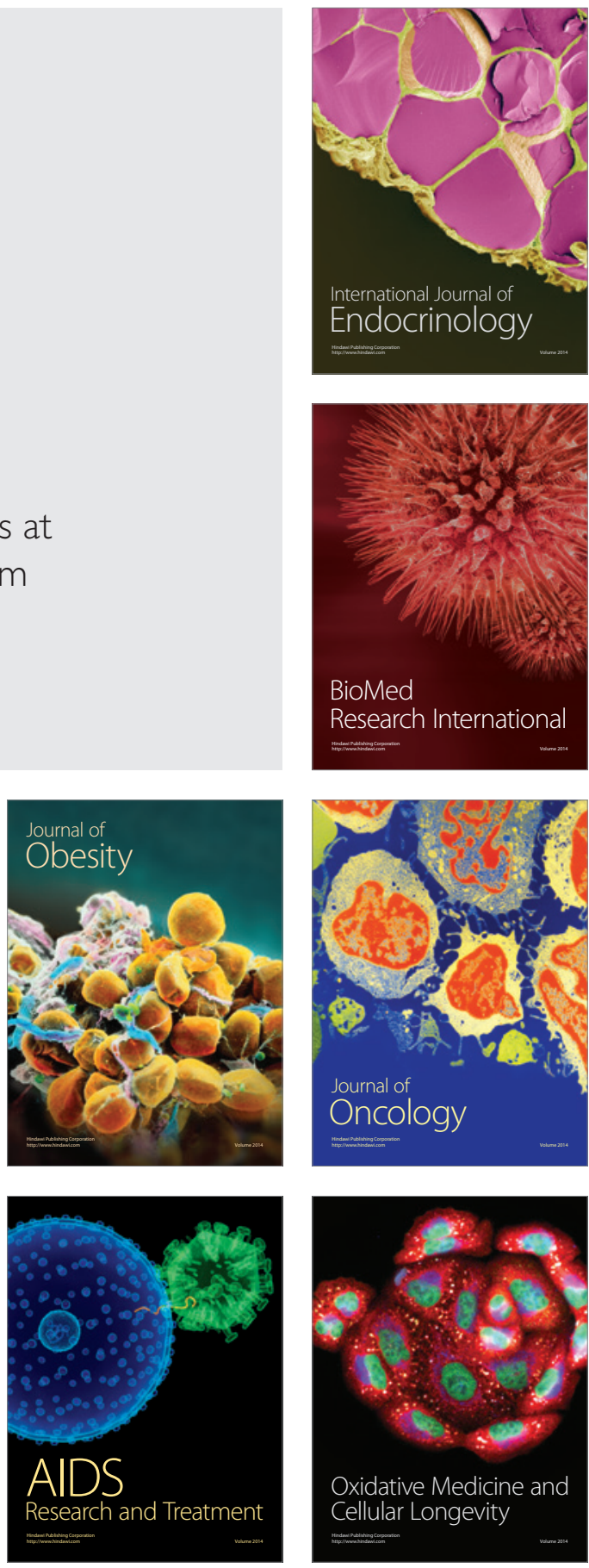